\title{
Somatic growth following the modified Fontan procedure
}

\author{
Robert Weintraub, Samuel Menahem \\ Department of Cardiology, Royal Children's Hospital, Melbourne, Australia
}

I $N$ THE PRESENT ISSUE OF THIS JOURNAL, THERE ARE two seemingly contradictory reports of long-term growth following definitive palliation of children with functionally univentricular physiology. ${ }^{1,2}$ Cohen and colleagues ${ }^{1}$ detail the growth of 65 children undergoing the modified Fontan procedure at a mean age of 20 months, following an early cavopulmonary connection. At long-term follow-up, the mean weight and height $Z$ scores were -0.49 and -1.15 , respectively. Despite generally satisfactory haemodynamics at subsequent cardiac catheterisation, the mean $Z$ scores for both parameters remained significantly below normal, and below those of healthy siblings. These results could not be explained by persisting hypoxaemia after a modified Fontan procedure, nor by the occurrence of a protein losing enteropathy, which occurred in $7 \%$ of the population studied. The only convincing effect on growth was the modest improvement in $\mathrm{Z}$ scores for weight following the initial cavopulmonary connection.

In contrast, Stenbøg and colleagues ${ }^{2}$ report improved growth in a cohort of 20 children who underwent various forms of cavopulmonary connection at a mean age of 8.5 years. At latest follow-up the mean postoperative $\mathrm{z}$ scores for weight and height were 0.0 and +0.3 , respectively. Levels of insulin-like growth factor measured in the serum were within the normal range, and were comparable to those of 33 control subjects without congenital heart disease.

How can two apparently similar studies report such differing results? Each study needs to be interpreted with some caution. The proportion of children excluded for various reasons from the

Correspondence to: Robert Weintraub and Samuel Menahem, Department of Cardiology, Royal Children's Hospital, Flemington Road, Parkville, Victoria 3052 Australia. Tel: $61 \quad 3 \quad 345$ 5717; Fax: $61 \quad 3 \quad 3474$ 5708; E-mail weintrar@cryptic.rch.unimelb.edu.au

Accepted for publication 3 July 2000 study of Stenbøg and colleagues ${ }^{2}$ has not been specified. The degree of preoperative disturbance of growth was less severe than in the study by Cohen et al. ${ }^{1}$ The variable timing of the pubertal growth spurt potentially confounds interpretation of crosssectional growth parameters and levels of growth factors among children of widely varying ages.

There are multiple reasons why children with surgically corrected cardiac malformations may fail to attain normal postoperative growth, even when those with syndromal or chromosomal anomalies, and those with major extracardiac malformations, are excluded from consideration. ${ }^{3}$ Low birthweight for gestational age is over-represented in most categories of congenital heart disease. Children with a birthweight below the 10th percentile for gestational age usually manifest persisting impairment of growth after curative surgery, such as closure of a ventricular septal defect ${ }^{4}$ or an arterial switch procedure. ${ }^{5} \quad$ Although inadequate nutrition frequently plays a role in the impairment of growth of children with major cardiac malformations, ${ }^{6}$ additional mechanisms may contribute in hypoxaemic infants. Young cyanotic patients usually show earlier impairment of linear growth, along with more symmetrical depression of anthropometric indexes, than do acyanotic infants with large left-to-right shunts. It seems likely that hypoxaemia exerts a direct effect on linear growth. There is evidence for a critical vulnerable period, beyond which it may not be possible for children with some cardiac malformations to regain normal growth. ${ }^{7}$ There is little data about the extent to which catchup growth occurs following correction or palliation of cyanotic malformations beyond early infancy. Nor is it known whether a modest degree of continuing impairment of growth during childhood will be magnified by a delayed or incomplete growth spurt after onset of puberty.

Perhaps the most important difference between the two studies lies in the selection of the population 
studied. In the report of Cohen and colleagues, ${ }^{1}$ infants with hypoplastic left heart syndrome accounted for over half of the population, and nearly seven-tenths in total required a first stage Norwood procedure. The cumulative negative impact on growth and nutritional status of moderate hypoxaemia in combination with increased pulmonary blood flow is manifest by the disproportionate reduction in mean $Z$ scores for weight relative to those for height at the time of the cavopulmonary connection. Despite the excellent surgical results obtained by these authors, the additional complexity of care required to treat these patients is evident in the reintervention rate of $45 \%$ following the modified Fontan, and in the number of non-cardiac complications. No doubt a proportion of patients who needed late intervention were symptomatic from hypoxaemia, congestive heart failure, or a protein losing enteropathy. By contrast, the study of Stenb $\varnothing \mathrm{g}$ and colleagues ${ }^{2}$ contains a high proportion of patients who would be considered ideal Fontan candidates, none of whom required a first stage Norwood procedure or late reintervention.

In an era when the presence of a major cardiac malformation represents the main indication for surgery, and when the timing of surgery is dictated by feasibility, should paediatric cardiologists be concerned by somatic sequels of treated congenital heart disease? The answer must surely be yes. In many centres, somatic growth and symptoms are taken into consideration when deciding on therapy in children with certain cardiac malformations. Collection of long-term data about our patients enhances our ability to provide appropriate and factual counselling to parents who are confronted with difficult decisions. If the primary goal of paediatric cardiologists and surgeons is to create productive adults who function normally, documentation of noncardiac sequels in our patients is an essential component of our labours.

\section{References}

1. Cohen MI, Bush DM, Ferry RJ, Spray TL, Moshang T, Wernovsky $G$, Vetter $V_{L}$. Somatic growth failure after the Fontan operation. Cardiol Young 2000;10: 447-457.

2. Stenbøg EV, Hjortdal VE, Ravn HB, Skjaerbaek C, Sorensen $\mathrm{KE}$, Hansen $\mathrm{OK}$. Growth improvement and insulin-like growth factor-I after cavo-pulmonary connections. Cardiol Young 2000;10: 440-446.

3. Weintraub RG, Menahem S. Growth and congenital heart disease. J Paediatr Child Health 1993;29: 95-8.

4. Weintraub RG, Menahem S. Early surgical closure of a large ventricular septal defect: influence on long-term growth. J Am Coll Cardiol 1991;18: 552-558.

5. Swan J, Weintraub RG, Radley-Smith R, Yacoub M. Long-term growth following anatomic repair of transposition of the great arteries. Clin Cardiol 1993: 16: 392-396.

6. Barton JS, Hindmarsh PC, Preece MA. Serum insulin-like growth factor $I$ in congenital heart disease. Arch Dis Child 1996; 75: 162-163.

7. Levy RJ, Rosenthal A, Miettinen OS, Nadas AS. Determinants of growth in patients with ventricular septal defect. Circulation 1978; $57: 793-797$. 